\title{
Mortality and major morbidities in very preterm infants born from assisted conception or naturally conceived: results of the area-based ACTION study
}

Carlo Corchia ${ }^{1 *}$, Monica Da Frè2 ${ }^{2}$ Domenico Di Lallo ${ }^{3}$, Luigi Gagliardi ${ }^{4}$ Franco Macagno ${ }^{5}$, Virgilio Carnielli ${ }^{6}$, Silvana Miniaci ${ }^{7}$ and Marina Cuttini ${ }^{8}$

\begin{abstract}
Background: The use of assisted conception (AC) has been associated with higher risk of adverse perinatal outcome. Few data are available on the outcome of AC-neonates when pregnancy ends before 32 weeks of gestational age.

The aim of this study was to compare the short-term outcome of AC- and naturally conceived preterm infants $<32$ weeks gestation.

Methods: The area-based cohort study ACTION collected data on births 22-31 weeks gestation occurred in 2003-05 in 6 Italian regions. Infants born to 2529 mothers with known mode of conception were studied. The main outcomes were hospital mortality and survival free from major morbidities (IVH grade 3-4, CPVL, ROP stage $\geq 3, \mathrm{BPD}$ ), and were assessed separately for single and multiple infants. Other outcomes were also investigated. Multivariable logistic analyses were used to adjust for maternal and infants' characteristics. To account for the correlation of observations within intensive care units, robust variance and standard error estimates of regression parameters were computed.

Results: AC was used in 6.4\% of mothers. Infants were 2934; 314 (10.7\%) were born after AC. Multiples were 86.0\% among $A C$ and $21.7 \%$ among non-AC babies. In multivariable analysis no statistically significant difference in hospital mortality and survival without major morbidities was found between AC and non-AC infants. The risk of BPD was lower in AC than in non-AC multiples (aOR 0.41, Cl 0.20-0.87), and this finding did not change after controlling for mechanical ventilation (aOR 0.42, Cl 0.20-0.85) or presence of a patent ductus arteriosus (aOR 0.39, Cl 0.18-0.84).

Conclusion: When the analysis is restricted to very preterm infants and stratified by multiplicity, no significant associations between AC and increased risk of short-term mortality and survival without major morbidities emerge. This result is consistent with previous studies, and may confirm the hypothesis that the adverse effects of AC are mediated by preterm birth. However, larger appropriately powered studies are needed before definitely excluding the possibility of adverse events linked to $A C$ in infants born before 32 weeks gestation.
\end{abstract}

Keywords: Assisted conception, Preterm birth, Neonatal mortality, Neonatal morbidity, Singletons, Multiples

\footnotetext{
*Correspondence: corchiacarlo@virgilio.it

${ }^{1} \mathrm{ICBD}$, International Centre on Birth Defects and Prematurity, via Carlo

Mirabello 14, 00195 Rome, Italy

Full list of author information is available at the end of the article
} 


\section{Background}

Births after Assisted Conception (AC) have increased in the last decades in industrialized countries, currently accounting for over $1 \%$ of all livebirths in the USA, nearly $2 \%$ in Italy and UK, and up to $6 \%$ in other European countries [1-3]. As a consequence, concerns have been raised about possible increased risks of adverse pregnancy and infant outcomes, in particular after the use of assisted reproductive technologies (ART) that involve gamete manipulation outside the reproductive systems. Multiple pregnancy, placenta praevia, antepartum haemorrhage, incompetent cervix, pregnancy-induced hypertension, preterm birth, low birth weight, foetal growth restriction, birth defects, caesarean delivery, and admission of newborn babies to neonatal intensive care unit (NICU) have been reported [4-7]. Risks appear to be higher in single compared to multiple births $[8,9]$. Open issues still remain, mainly related to the potential confounding effects of maternal sociodemographic characteristics and lifestyles, the possibility of spontaneous reduction in case of multifoetal pregnancy, the effect of infertility "per se" and of the different technical approaches adopted [4].

Most of the adverse neonatal outcomes after AC are linked to the increased risk of prematurity. When the analysis was restricted to infants born before 32 weeks gestation (Very Preterm Infants, VPI) or with birth weight $<1500 \mathrm{~g}$ (Very Low Birth Weight Infants, VLBWI), no excess mortality and morbidity linked to AC was found [10-15]; nor there was an increased emotional burden in mothers after AC during the neonatal period [16]. However, with the exception of one area-based [12] and one multi-centre hospital based [10] studies, most of the evidence is derived from retrospective single-centre investigations [11,13-16].

In this study we used the data of a large area-based prospective cohort study aiming at comparing the neonatal outcomes of AC- and naturally conceived VPI, separately for singletons and multiples.

\section{Methods}

\section{Study population}

The ACTION (Accesso alle Cure e Terapie Intensive Ostetriche e Neonatali ) project was a prospective areabased cohort study carried out in 6 Italian regions: two in the North (Lombardia and Friuli Venezia-Giulia), three in the Centre (Toscana, Marche and Lazio) and one in the South of Italy (Calabria). Overall, about $40 \%$ of all Italian births take place in these regions.

All mothers of infants born at 22 to 31 completed weeks of gestational age (GA) and admitted to NICU between July 2003 and December 2004 in Lombardia, Lazio and Calabria, and up to June 2005 in Friuli Venezia-Giulia, Tuscany and Marche were enrolled in the study $(n=2660)$. Infants were followed up to discharge from hospital or death in NICU.
The study was approved by the Paediatric Ethics Committee of Tuscany, that was the project-leader region. Parental written informed consent was obtained.

\section{Data collection}

A standardized form was used to collect information on mothers' characteristics, pregnancy complications and care, babies' conditions and assistance at birth, morbidities and treatments in the NICU, outcome at discharge from hospital. Assisted conception was defined as any kind of treatment for infertility, including techniques that assist the egg fertilization and implantation. GA was recorded, in completed weeks and days, as the best obstetrical estimate using information on the last menstrual period and ultrasound measures. According to the Italian guidelines, the ultrasound GA estimate was used instead of that based on the date of the last menstrual period when the difference between the two was $\geq 1$ week and the ultrasound evaluation was performed within 16 weeks gestation [17]. The level of centre of birth was defined as tertiary when a $3^{\text {rd }}$ level NICU was present in the same hospital. Complications in pregnancy were defined according to the MOSAIC study [18], and grouped into a) disorders of placentation, including pregnancy hypertension disorders, HELLP syndrome, pre-eclampsia, eclampsia, and foetal growth restriction, and b) intrauterine inflammation/infection, including threatened preterm birth, preterm premature rupture of membranes, antepartum haemorrhage and maternal infection [19]. Small for gestational age (SGA) infants were those whose birth weight was below the $10^{\text {th }}$ percentile, derived from this same cohort by week of gestation and sex. We used the $10^{\text {th }}$ percentile cutoff because it is the most frequently quoted in the literature, and was adopted in other areabased European research projects [18,20,21].

Main infants' outcomes were defined as death before discharge and survival without major morbidities. The last included: intraventricular haemorrhage (IVH, grade 3-4) [22], cystic periventricular leukomalacia (c-PVL, grade 2-4) [23], retinopathy of prematurity (ROP, stage $\geq 3$ ), and bronchopulmonary dysplasia (BPD, defined as need for oxygen supplementation at 36 weeks GA or at discharge for infants discharged earlier). Other outcomes were ultrasound diagnosed patent ductus arteriosus (PDA), necrotizing enterocolitis (NEC stage 2 or 3, modified Bell's criteria) [24], any sepsis or meningitis (clinical and hematological signs \pm positive culture), length of hospitalization for survivors, and any breastfeeding at discharge.

\section{Statistical analysis}

Single and multiple infants were considered separately.

Univariate chi-squared or $\mathrm{t}$ test calculation were used as appropriate to explore the relationships between $\mathrm{AC}$ 
and maternal characteristics, pregnancy complications and infants' variables.

Multivariable logistic regression models were used to assess the association between $\mathrm{AC}$ and infant outcomes, adjusting for potential confounders. Robust variance and standard error estimates of regression parameters were calculated using the clustered sandwich estimator method, to account for the intra-group correlation of observations within NICUs [25]. The following variables were controlled for: gender, any antenatal steroids, GA in completed weeks, SGA status, mode of delivery, region of birth and maternal variables. These included maternal age (coded as $<35$ or $\geq 35$ years), country of origin (Italy or otherwise), education (primary/lower secondary versus upper secondary/university), and any previous births (yes or no). Missing data in the explanatory variables were included in the models as dummies. Missing values were always $\leq 5 \%$, with the exception of maternal age and education (missing $7 \%$ and $14 \%$ respectively).

Results are presented in tables as absolute and relative frequencies, and as adjusted odds ratios (aOR) and 95\% confidence intervals $(\mathrm{CI})$. Frequencies of neonatal morbidities were computed on infants surviving to diagnostic ascertainment, or to 36 weeks GA age for BPD.

The STATA software, version 10 (StataCorp 2007. Stata statistical software: Release 10. College Station, TX: StataCorp) was used for statistical analyses. Power analysis for multiple logistic regression was performed with the PASS 13 software (NCSS, LLC, Kaysville, Utah, USA) [26].

Data were reported and discussed according to the STROBE statement checklist for observational cohort studies (www.strobe-statement.org) (Additional file 1).

\section{Results}

One hundred and thirty one mothers (4.9\%) were excluded because mode of conception was unknown (Figure 1). AC was employed in 163 of the remaining 2529 mothers (6.4\%). Details about the technique used were available for 113 births: in vitro fertilization (IVF) or intracytoplasmic sperm injection (ICSI) was used in $68 \%$ of them. The overall frequency of multiple births was $16.1 \%(n=407): 73.0 \%$ $(\mathrm{n}=119)$ in $\mathrm{AC}$ group and $12.2 \%(\mathrm{n}=288)$ in non- $\mathrm{AC}$ group. Liveborn infants were 2934 (314 following AC, $10.7 \%) ; 27.7 \%$ of them were multiples $(\mathrm{n}=812)$, and $72.3 \%$ were singletons $(\mathrm{n}=2122)$.

$\mathrm{AC}$ use was significantly more frequent when mothers were older and more educated, and less frequent in foreign mothers and after previous births (Table 1). No statistically significant differences in pregnancy complications, GA distribution and administration of antenatal steroids were found between non-AC and AC pregnancies. Twin, triplet and quadruplet births were more frequent following AC. Mothers with AC pregnancies were more likely to have a spontaneous onset of labour, be delivered in a tertiary centre, and have a caesarean section.

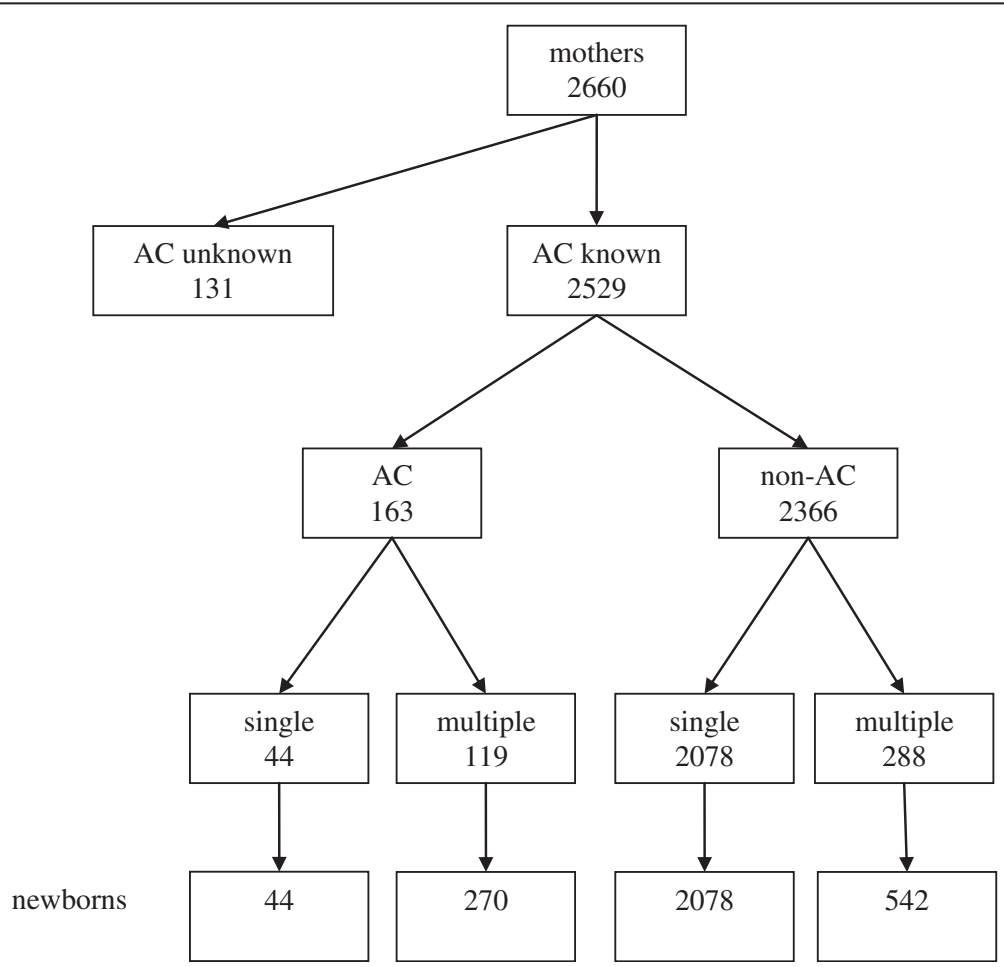

Figure 1 Description of the cohort under study. 
Table 1 Maternal, pregnancy and delivery variables, by mode of conception $(n=2529)$

\begin{tabular}{|c|c|c|c|c|c|}
\hline & \multicolumn{2}{|c|}{ Non-AC } & \multicolumn{2}{|l|}{ AC } & \multirow[t]{2}{*}{$p$-value } \\
\hline & $\bar{n}$ & (\%) & $\bar{n}$ & (\%) & \\
\hline Age $\geq 35$ years & 703 & (31.9) & 69 & $(45.4)$ & $<0.001$ \\
\hline Country of origin other than Italy & 541 & $(23.2)$ & 16 & (9.9) & $<0.001$ \\
\hline Upper secondary/university education & 1206 & (59.6) & 108 & $(78.3)$ & $<0.001$ \\
\hline Previous births & 937 & $(40.4)$ & 30 & $(18.5)$ & $<0.001$ \\
\hline \multicolumn{6}{|l|}{ Plurality } \\
\hline Twin & 264 & (11.6) & 75 & $(46.0)$ & \\
\hline Triplet & 14 & $(0.6)$ & 42 & $(25.8)$ & $<0.001$ \\
\hline Quadruplet & 0 & & 2 & $(1.2)$ & \\
\hline \multicolumn{6}{|l|}{ Complications of pregnancy } \\
\hline Disorders of placentation ${ }^{1}$ & 731 & (31.4) & 46 & (28.4) & 0.431 \\
\hline Inflammation/infection ${ }^{2}$ & 1446 & (61.9) & 109 & (67.3) & 0.170 \\
\hline \multicolumn{6}{|l|}{ Gestational age at delivery (weeks) } \\
\hline$<26$ & 345 & (14.6) & 28 & $(17.2)$ & 0.606 \\
\hline $26-27$ & 412 & $(17.4)$ & 23 & $(14.1)$ & \\
\hline $28-29$ & 591 & $(25.0)$ & 39 & $(23.9)$ & \\
\hline $30-31$ & 1018 & $(43.0)$ & 73 & $(44.8)$ & \\
\hline Delivery at tertiary centre & 2108 & $(89.1)$ & 154 & $(94.5)$ & 0.031 \\
\hline Any antenatal steroids & 1741 & $(76.4)$ & 131 & (81.9) & 0.111 \\
\hline Spontaneous onset of labour & 1014 & $(43.8)$ & 84 & $(52.8)$ & 0.027 \\
\hline Caesarean delivery & 1687 & (71.6) & 130 & $(79.7)$ & 0.025 \\
\hline
\end{tabular}

${ }^{1}$ Disorders of placentation include: pregnancy hypertension disorders, HELLP syndrome, pre-eclampsia, eclampsia, foetal growth restriction.

${ }^{2}$ Inflammation/infection disorders include: threatened preterm labor, PPROM, antepartum haemorrhage, maternal infection.

Infants' characteristics and outcomes by plurality and mode of conception are shown in Table 2. Females were more frequent among AC singletons. Frequencies of mechanical ventilation, $\mathrm{PDA}$, and BPD were lower in AC compared to non-AC multiples. A shorter length of hospitalization was observed in surviving AC multiples.

In multivariable analyses (Table 3 ), the aOR point estimates for hospital mortality and survival without major morbidities were 1.60 and 0.75 respectively in singletons, and 0.79 and 1.30 in multiples. The associations were not significant as all the CIs included unity. However, the statistical power estimates were low, ranging from 0.23 for mortality and 0.13 for survival without major morbidities in singletons, and 0.13 and 0.25 for the two outcomes, respectively, in multiples. We cannot therefore exclude that a much larger study might have led to statistically significant results.

Similar non-significant differences were found for the other morbidity outcomes in singletons, although in some cases the aOR point estimates were well above 2 (severe IVH) or below 0.5 (sepsis/meningitis). Among multiples, however, statistically significant lower risks for PDA (aOR 0.64, CI 0.45-0.90) and BPD (aOR 0.41, CI 0.20-0.87) were found, while for NEC the decreased risk (aOR 0.44, CI 0.19-1.02) was at borderline significance.
The association between AC and PDA in multiples remained statistically significant after adjustment for mechanical ventilation (aOR $0.68, \mathrm{CI} 0.48-0.97$ ), and that with BPD did not change after controlling for ventilation or PDA, (aORs 0.42, CI $0.20-0.85$, and 0.39, CI 0.180.84 , respectively).

\section{Discussion}

In this area-based cohort of very preterm infants we could not demonstrate clear differences in mortality and survival without major morbidities between naturally and $\mathrm{AC}$-conceived babies.

To some extent our findings are comparable to those of previous studies in very preterm or VLBWI. Stewart et al. [10] studied 1473 VLBWI, and found no difference in cranial ultrasound abnormalities between naturally conceived babies and those born after ART or use of fertility therapy. In multiple VLBWI Hashimoto et al. [11] found no difference in mortality, BPD, and the combined outcome mortality or BDP between naturally conceived babies and those conceived following fertility treatment. In a large population of VLBWI, Schimmel et al. [12] found no difference in mortality, respiratory distress syndrome, PDA, NEC, IVH, BPD, and congenital malformations between babies born after IVF $(n=1396)$ and those 
Table 2 Infants' characteristics and short term outcomes by plurality and mode of conception $(n=2934)$

\begin{tabular}{|c|c|c|c|c|c|c|c|c|c|c|}
\hline & \multicolumn{5}{|c|}{ Singletons } & \multicolumn{5}{|c|}{ Multiples } \\
\hline & \multicolumn{2}{|c|}{ Non-AC $(n=2078)$} & \multicolumn{2}{|c|}{$A C(n=44)$} & \multirow[t]{2}{*}{$p$ value } & \multicolumn{2}{|c|}{ Non-AC $(n=542)$} & \multicolumn{2}{|c|}{$A C(n=270)$} & \multirow[t]{2}{*}{ p value } \\
\hline & $\mathrm{n}$ & $(\%)$ & $\mathrm{n}$ & $(\%)$ & & $\mathrm{n}$ & $(\%)$ & $\mathrm{n}$ & $(\%)$ & \\
\hline Gender, females & 944 & $(45.5)$ & 27 & $(61.4)$ & 0.036 & 255 & $(47.0)$ & 128 & $(47.4)$ & 0.923 \\
\hline SGA & 217 & $(10.5)$ & 6 & $(13.6)$ & 0.498 & 41 & $(7.6)$ & 16 & $(6.0)$ & 0.393 \\
\hline \multicolumn{11}{|l|}{ Malformations } \\
\hline Lethal & 2 & $(0.1)$ & 0 & & & 0 & & 0 & & 0.265 \\
\hline Acutely life-threatening & 35 & $(1.8)$ & 0 & & 0.790 & 4 & $(0.8)$ & 0 & & \\
\hline Non acutely life-threatening & 105 & (5.3) & 3 & $(7.1)$ & & 23 & $(4.4)$ & 8 & $(3.1)$ & \\
\hline Apgar score $<7 /$ intubated at $5 \mathrm{~m}^{\prime}$ & 965 & $(47.1)$ & 23 & $(52.3)$ & 0.500 & 218 & $(40.7)$ & 101 & $(38.1)$ & 0.474 \\
\hline \multicolumn{11}{|l|}{ CRIB score } \\
\hline$>2$ & 773 & $(41.4)$ & 17 & $(41.5)$ & 0.758 & 158 & $(32.8)$ & 77 & $(32.8)$ & 0.777 \\
\hline not attributed & 213 & $(13.2)$ & 3 & $(6.8)$ & & 61 & $(11.2)$ & 35 & $(13.0)$ & \\
\hline Any surfactant & 1164 & $(57.3)$ & 29 & $(69.0)$ & 0.129 & 300 & $(56.7)$ & 139 & $(53.0)$ & 0.330 \\
\hline nCPAP & 1462 & $(72.3)$ & 33 & $(78.6)$ & 0.368 & 357 & $(68.3)$ & 167 & $(64.2)$ & 0.259 \\
\hline Mechanical ventilation & 1272 & $(62.7)$ & 31 & $(72.1)$ & 0.205 & 316 & $(60.3)$ & 138 & $(52.5)$ & 0.036 \\
\hline PDA & 798 & $(42.5)$ & 20 & $(55.6)$ & 0.116 & 243 & $(50.7)$ & 101 & $(42.8)$ & 0.046 \\
\hline NEC & 69 & (3.5) & 0 & & 0.226 & 20 & (3.8) & 6 & $(2.4)$ & 0.286 \\
\hline Sepsis/meningitis & 442 & $(21.8)$ & 7 & $(16.7)$ & 0.425 & 106 & $(20.0)$ & 48 & $(18.4)$ & 0.591 \\
\hline IVH grade 3 or 4 & 166 & $(8.5)$ & 6 & $(14.3)$ & 0.188 & 52 & $(10.3)$ & 25 & $(9.9)$ & 0.865 \\
\hline c-PVL & 99 & $(5.1)$ & 0 & & 0.142 & 32 & $(6.23)$ & 12 & $(4.8)$ & 0.393 \\
\hline ROP stage $\geq 3$ & 79 & $(4.3)$ & 1 & $(2.9)$ & 0.676 & 17 & (3.7) & 5 & $(2.1)$ & 0.280 \\
\hline $\mathrm{BPD}$ & 219 & $(12.7)$ & 6 & $(17.1)$ & 0.433 & 44 & $(10.1)$ & 9 & $(4.2)$ & 0.010 \\
\hline Death before discharge & 364 & $(17.6)$ & 9 & $(20.9)$ & 0.566 & 110 & $(20.4)$ & 52 & $(19.3)$ & 0.709 \\
\hline Survival without major morbidities ${ }^{1}$ & 1356 & $(65.4)$ & 26 & $(60.5)$ & 0.500 & 363 & $(67.2)$ & 191 & $(70.7)$ & 0.310 \\
\hline Any breast feeding at discharge & 1001 & $(59.8)$ & 23 & $(74.2)$ & 0.105 & 255 & $(61.3)$ & 135 & $(63.4)$ & 0.611 \\
\hline Lenght of stay, survivors Days, mean (sd) & 64.6 & $(34.3)$ & 61.9 & $(31.2)$ & $0.653^{2}$ & 60.2 & $(33.2)$ & 54.5 & $(27.7)$ & $0.031^{2}$ \\
\hline
\end{tabular}

SGA: Small for gestational age; nCPAP: Nasal continuous positive airway pressure; PDA: Patent ductus arteriosus; NEC: Necrotizing enterocolitis; IVH: Intraventricular haemorrhage; C-PVL: Cystic periventricular leukomalacia; ROP: Retinopathy of prematurity; BPD: Bronchopulmonary dysplasia. Frequencies of morbidities were computed on babies who survived to have the relevant diagnostic ascertainment or up to 36 weeks GA for BPD.

${ }^{1}$ Major morbidities defined as: IVH grade $3-4$, c-PVL, ROP stage $\geq 3$, BPD.

${ }^{2}$ t test.

naturally conceived $(\mathrm{n}=6765)$. Messerschmidt et al. [13] compared 195 VLBWI born after IVF with 1228 naturally conceived VLBWI, and found no difference in mortality, short term pulmonary morbidity, severe cerebral morbidity and frequency of SGA babies. Shah et al. [14] compared the neonatal outcome of 137 multiple infants $\leq 32$ weeks GA born after ART with that of 233 naturally conceived multiple babies with similar GA, and found no difference in outcome defined as a combination of death, grade $3 / 4 \mathrm{IVH}$ or periventricular leukomalacia, ROP stage $>2$, and chronic lung disease. Picaud et al. [15] reported survival without severe morbidity in 612 infants $<33$ weeks GA: 81 were born following ART and 521 were naturally conceived. Using a composite morbidity index based on the occurrence of NEC, IVH grade $\geq 3$, periventricular leukomalacia, and BPD, these authors found that survival without severe morbidity was higher in ART infants.
Most of the unfavourable neonatal outcomes reported when also moderate/late preterm and term infants are included in the study populations are probably the consequence of the shift of GA distribution toward lower values; this shift is predominantly related to the higher frequency of multiplicity, but it was observed also in single pregnancies [4,8,27-29]. Causes of infertility, in adjunct to and independently from factors related to the reproductive technology itself, may also contribute to the unfavorable outcomes associated with AC [30]. However, when only very preterm or very low birth weight infants are considered, the effect of multiplicity on gestational age does not apply, and both AC- and naturally conceived infants are exposed to the adverse influence of very early birth and immaturity of organs. Additionally, AC pregnancies may benefit from the better prenatal and perinatal care associated with medically assisted reproduction, 
Table 3 Adjusted odds ratios (aOR) of neonatal morbidity and mortality outcomes comparing AC and non-AC babies, separately for singletons and multiples

\begin{tabular}{|c|c|c|c|c|}
\hline & \multicolumn{2}{|c|}{ Singletons } & \multicolumn{2}{|c|}{ Multiples } \\
\hline & $\mathrm{aOR}^{1}$ & $95 \% \mathrm{Cl}$ & $\mathrm{aOR}^{1}$ & $95 \% \mathrm{Cl}$ \\
\hline$\overline{\mathrm{PDA}}$ & 1.63 & $0.84-3.16$ & 0.64 & $0.45-0.90$ \\
\hline $\mathrm{IVH}$, grade $3-4$ & 2.40 & $0.93-6.19$ & 1.08 & $0.52-2.23$ \\
\hline C-PVL & $-{ }^{2}$ & - & 1.09 & $0.46-2.58$ \\
\hline IVH grade 3-4 or c-PVL & 1.36 & $0.59-3.14$ & 1.00 & $0.55-1.81$ \\
\hline Sepsis/meningitis & 0.48 & $0.20-1.17$ & 0.89 & $0.53-1.47$ \\
\hline NEC & -2 & - & 0.44 & $0.19-1.02$ \\
\hline ROP, stage $\geq 3$ & 0.57 & $0.06-5.51$ & 0.36 & $0.11-1.15$ \\
\hline $\mathrm{BPD}$ & 1.37 & $0.58-3.23$ & 0.41 & $0.20-0.87$ \\
\hline Death before discharge & 1.60 & $0.72-3.54$ & 0.79 & $0.47-1.33$ \\
\hline Survival without major morbidities & 0.75 & $0.43-1.30$ & 1.30 & $0.85-1.99$ \\
\hline
\end{tabular}

PDA: Patent ductus arteriosus; IVH: Intraventricular haemorrhage; c-PVL: Cystic periventricular leukomalacia; $N E C$ : Necrotizing enterocolitis; ROP: Retinopathy of prematurity; $B P D$ : Bronchopulmonary dysplasia.

aORs indicate the association between $\mathrm{AC}$ and outcomes, adjusting for gender, antenatal steroids, gestational age, SGA status $\left(<10^{\text {th }}\right.$ BW percentile), mode of delivery, region of birth, and mothers' characteristics (age, country of origin, education, and previous births).

${ }^{2}$ No estimation of the aORs was possible because no cases of c-PVL and NEC were reported for $\mathrm{AC}$ singletons.

including earlier contact with the obstetric services and more careful monitoring of mother and foetus conditions $[15,31]$. It is also possible that pre-pregnancy health and lifestyles of mothers determined to conceive and ultimately accessing $\mathrm{AC}$ services are more favourable than in naturally conceiving women and able to promote better perinatal outcomes [32].

Indeed in our study women using $\mathrm{AC}$, although older than those who conceived naturally, did not seem to have increased rates of pregnancy inflammation/infection or disorders of placentation that have been linked with different patterns of placental pathologies and foetal/ neonatal outcomes $[19,33,34]$. They were also more likely to be Italian and to have a higher education, and therefore have access to the information and contacts that facilitate healthier lifestyles and better health care.

We found that, compared to non-AC peers, AC multiples had a lower risk of BPD, and this result persisted after adjustment for PDA and mechanical ventilation, two possible antecedents of BPD. Previous studies reported inconclusive results about BPD. Schimmel et al. found no difference in risk of chronic lung disease in single and multiple VLBWI according to mode of conception [12], while Picaud et al. reported a lower BPD rates in infants $<29$ weeks gestation born after ART [15]. In contrast, Shah et al. found higher rates of BPD in ART preterm multiples less than 33 weeks gestation compared to naturally conceived peers [14].

These results are not directly comparable with ours because of differences in study design (centre-based rather than area-based) or eligibility criteria (birth weight rather than gestational age). Other studies including both preterm and at-term twins found better perinatal outcomes in ART- than in naturally conceived infants $[31,35]$. Most unlikely these differences can be causally linked to specific ART treatment effect. As already discussed, better pre-pregnancy health and perinatal care associated with medically assisted reproduction may result in offspring with more favourable clinical conditions.

This study has limitations. As in most studies focusing on the special populations of very preterm or very low birth weight infants (about 1-1.5\% of total births), sample size may be not large enough to detect the neonatal outcomes associated with AC. Also, we were not able to separately investigate the risks of the different $\mathrm{AC}$ technologies, particularly those involving manipulation of gametes outside the reproductive system, such as IVF and ICSI. Nevertheless, the worse outcome in AC than in non-AC singletons suggested by our findings, and the reverse trend in multiple babies, is in agreement with the worse outcomes in AC-conceived singletons reported in recent meta-analyses $[29,36]$.

The strengths of this study are the area-based prospective design, thus averting selection biases caused by a centre-based approach. Additionally, and unlike most previous studies, recruitment was based on GA, which prevented the bias arising when the birth weight criterion is employed to study the relationship between antenatal and perinatal factors and neonatal outcomes.

\section{Conclusion}

In our population of newborn infants $<32$ weeks GA, although a lower risk of some short-term outcomes, such as PDA and BPD, was found in AC-multiples, we could not demonstrate the presence or absence of different risks of mortality and survival without major morbidities in AC compared to non-AC conceived babies. A final conclusion about differences of outcomes in VPI born from assisted conception or naturally conceived cannot therefore be reached. Although some of our results may be of interest and suggest clues for clinical interpretations, larger and more powered studies are needed before confidently exclude the effects of $\mathrm{AC}$ on the short term outcomes of very preterm infants. To this end, this study can serve as a suitable pilot investigation.

\section{Additional file}

Additional file 1: STROBE Statement-Checklist of items that

should be included in reports of cohort studies.

\section{Abbreviations}

AC: Assisted conception; ART: Assisted reproductive technology;

NICU: Neonatal intensive care unit; VPI: Very preterm infants; VLBWI: Very low birth weight infants; GA: Gestational age; PDA: Patent ductus arteriosus; 
NEC: Necrotizing enterocolitis; IVH: Intraventricular haemorrhage; c-PVL: Cystic periventricular leukomalacia; ROP: Retinopathy of prematurity; BPD: Bronchopulmonary dysplasia; SGA: Small for gestational age; IVF: In vitro fertilization; ICSI: Intracytoplasmic sperm injection.

\section{Competing interests}

The authors declare that they have no competing interests.

\section{Authors' contributions}

CC participated in the project design, conceived the analyses and drafted the manuscript. MC was the project leader, coordinated data collection and management, supervised statistical analysis and participated in the preparation of the manuscript. MDF carried out statistical analyses and prepared tables and figure. DDL, LG, FM, VC and SM contributed to the overall project design, instrument preparation, and acquisition of data. All Authors contributed to the interpretation of the results and critically revised the paper, and have seen and approved the submission of this version of the manuscript.

\section{Acknowledgements}

The results presented in this paper are part of the project on "Accesso alle Cure e Terapie Intensive Ostetrico-Neonatali" (ACTION). ACTION was funded by the Italian Ministry of Health (Programma di Ricerca Finalizzata 2002-2004) and coordinated by the Unit of Epidemiology of the Regional Agency for Health of Tuscany. We thank E. Coianiz, R. Da Riol and M. Montico (Friuli Venezia-Giulia), R. Bellù, M. Bellasio and M. Fusi (Lombardia), F. Sidoti, M. Giannelli and F. Rusconi (Tuscany), R. Freddara and L. Pellegrini (Marche), M. Barbolini, R Aduna, M. Di Renzi, and S. Santoni (Lazio) and S. Dodaro (Calabria), who monitored data collection at regional level. S. Alberico and G. Mello participated in the preparation of the data collection instrument, prenatal section.

We are very grateful to all the parents who agreed to participate in the project, and to the physicians and midwives who collected the data.

\section{Author details}

'ICBD, International Centre on Birth Defects and Prematurity, via Carlo Mirabello 14, 00195 Rome, Italy. ${ }^{2}$ Unit of Epidemiology, Regional Health Agency of Tuscany, Florence, Italy. ${ }^{3}$ Unit of Epidemiology, Regional Health Agency of Lazio, Rome, Italy. ${ }^{4}$ Woman and Child Health Department, Pediatrics and Neonatology Division, Versilia Hospital, Viareggio, Italy. ${ }^{5}$ Neonatal Intensive Care Unit, S. Maria della Misericordia University Hospital, Udine, Italy. ${ }^{6}$ Maternal and Child Health Institute, Marche University and Salesi Hospital, Ancona, Italy. ${ }^{7}$ Neonatal Intensive Care Unit, Pugliese-Ciaccio Hospital, Catanzaro, Italy. ${ }^{8}$ Unit of Epidemiology, Bambino Gesù Children's Hospital, Rome, Italy.

\section{Received: 20 July 2013 Accepted: 22 July 2014}

Published: 5 September 2014

\section{References}

1. Centers for Disease Control and Prevention: Assisted Reproductive Technology (ART) Report 2010. 2013. http://www.cdc.gov/art/artreports.htm accessed April 22, 2013.

2. Zeitlin J, Mohangoo AD, Delnord M, Cuttini M: EURO-PERISTAT Scientific Committee. The second European Perinatal Health Report: documenting changes over 6 years in the health of mothers and babies in Europe. J Epidemiol Community Health 2013, 67:983-985.

3. Human Fertilisation \& Embryology Authority, UK: Fertility Treatment in 2011: [http://www.hfea.gov.uk] accessed April 22, 2013.

4. Halliday J: Outcomes of IVF conceptions: are they different? Best Pract Res Clin Obstet Gynaecol 2007, 21:67-81.

5. Schieve LA, Cohen B, Nannini A, Ferre C, Reynolds MA, Zhang Z, Jeng G, Macaluso M, Wright WC: A population-based study of maternal and perinatal outcomes associated with assisted reproductive technology in Massachusetts. Matern Child Health J 2007, 11:517-525.

6. Davies MJ, Moore V, Willson K, Van Essen P, Priest K, Scott H, Haan EA, Chan A: Reproductive technologies and the risk of birth defects. N Engl J Med 2012, 366:1803-1813.

7. Wen J, Jiang J, Ding C, Dai J, Liu Y, Xia Y, Liu J, Hu Z: Birth defects in children conceived by in vitro fertilization and intracytoplasmic sperm injection: a meta-analysis. Fertil Steril 2012, 97:1331-1337.
8. McDonald SD, Han Z, Mulla S, Murphy KE, Beyene J, Ohlsson A: Preterm birth and low birth weight among in vitro fertilization singletons: a systematic review and meta-analyses. Eur J Obstet Gynecol Reprod Biol 2009, 146:138-148.

9. McDonald SD, Han Z, Mulla S, Ohlsson A, Beyene J, Murphy KE: Preterm birth and low birth weight among in vitro fertilization twins: a systematic review and meta-analyses. Eur J Obstet Gynecol Reprod Biol 2010, 148:105-113.

10. Stewart JE, Allred EN, Collins M, Abbott J, Leviton A, Paneth N, Reuss ML, Susser M, Hegyi T, Hiatt M, Sanocka U, Shahrivar F, Van Marter L, Banogan P, Genest D, Heller D, Shen-Schwarz S, Dammann O, Kuban KCK, Pagano M: Risk of cranial ultrasound abnormalities in very-low-birth-weight infants conceived with assisted reproductive techniques. J Perinatol 2002, 22:37-45.

11. Hashimoto LN, Lindsell CJ, Brewer DE, Eichel MM, Donovan EF: Contributions of infertility treatment to very-low-birth-weight multiple birth infants receiving neonatal intensive care. Am J Obstet Gynecol 2004, 190:401-406.

12. Schimmel MS, Hammerman C, Lusky A, Reichman B: Very low-birth-weightinfants conceived by in vitro fertilization are not at higher risk for mortality and morbidity: a population-based study. Fertil Steril 2006, 85:907-912.

13. Messerschimdt A, Olischar M, Bimbacher R, Weber M, Pollack A, Leitich $H$ : Perinatal outcome of preterm infants $<1500 \mathrm{~g}$ after IVF pregnancies compared with natural conception. Arch Dis Child Fetal Neonatal Ed 2010, 95:F225-F229.

14. Shah V, AlWassia H, Shah K, Yoon W, Shah P: Neonatal outcomes among multiple births in $\leq 32$ weeks gestational age: does mode of conception have an impact? a cohort study. BMC Pediatrics 2011, 11:54.

15. Picaud JC, Chalies S, Combes C, Mercier G, Dechaud H, Cambonie G: Neonatal mortality and morbidity in preterm infants born from assisted reproductive technologies. Acta Paediatr 2012, 101:846-851.

16. Tallandini MA, Morsan V, Macagno F: Preterm birth and assisted reproductive techniques/ART: maternal emotional wellbeing and quality of mother-infant interaction during the first three months of life. Early Hum Dev 2012, 88:397-402.

17. Italian Society for Obstetrical and Gynaecological Ecography: Guidelines 1010. Rome: 2010. [http://www.sieog.it/linee-guida/linee-guida-del-2010] Accessed November 9, 2013

18. Papiernik E, Zeitlin J, Delmas D, Blondel B, Künzel W, Cuttini M, Weber T, Petrou S, Gortner L, Kollée L, Draper ES, MOSAIC Group: Differences in outcome between twins and singletons born very preterm: results from a population-based European cohort. Hum Reprod 2010, 25:1035-1043.

19. McElrath TF, Hecht JL, Dammann O, Boggess K, Onderdonk A, Markenson G, Harper M, Delpapa E, Allred EN, Leviton A: Pregnancy disorders that lead to delivery before the 28th week of gestation: an epidemiologic approach to classification. Am J Epidemiol 2008, 168:980-989.

20. Zhang J, Merialdi M, Platt LD, Kramer MS: Defining normal and abnormal fetal growth: promises and challenges. Am J Obstet Gynecol 2010, 202:522-528.

21. Ancel P-Y, Marret S, Larroque B, Arnaud C, Zupan-Simunek V, Voyer M, Rozé J-C, Matis J, Burguet A, Ledésert B, André M, Pierrat V, Kaminski M, Epipage Study Group: Are maternal hypertension and small-for-gestational age risk factors for severe intraventricular hemorrhage and cystic periventricular leukonalacia? results of the EPIPAGE cohort study. Am J Obstet Gynecol 2005, 193:178-184.

22. Papile LA, Burstein J, Burstein R, Koffler H: Incidence and evolution of subependymal and intraventricular hemorrhage: a study of infants with birth weights less than 1,500 gm. J Pediatr 1978, 92:529-534.

23. de Vries LS: Neurological assessment of the preterm infant. Acta Paediatr 1996, 85:765-771.

24. Walsh MC, Kliegman RM: Review necrotizing enterocolitis: treatment based on staging criteria. Pediatr Clin North Am 1986, 33:179-201.

25. Williams RL: A note on robust variance estimation for cluster-correlated data. Biometrics 2000, 56:645-646.

26. Hsieh FY, Block DA, Larsen MD: A simple method of sample size calculation for linear and logistic regression. Stat Med 1998, 17:1623-1634.

27. Kalra SK, Molinaro TA: The association of in vitro fertilization and perinatal morbidity. Semin Reprod Med 2008, 26:423-425.

28. Williams C, Sutcliffe A: Infant outcomes of assisted reproduction. Early Hum Dev 2009, 85:673-677

29. Pinborg A, Wennerholm UB, Romundstad LB, Loft A, Aittomaki K, Soderstrom-Anttila V, Nygren KG, Hazekamp J, Bergh C: Why do singletons conceived after assisted reproduction technology have adverse perinatal 
outcome? systematic review and meta-analysis. Hum Reprod Update 2013, 19:87-104.

30. Romundstad LB, Romundstad PR, Sunde A, von Düring V, Skjærven R, Gunnell D, Vatten $L$ : Effects of technology or maternal factors on perinatal outcome after assisted fertilisation: a population-based cohort study. Lancet 2008, 372:737-743.

31. Boulet SL, Schieve LA, Nannini A, Ferre C, Devine O, Cohen B, Zhang Z, Wright V, Macaluso M: Perinatal outcomes of twin births conceived using assisted reproduction technology: a population-based study. Hum Reprod 2008, 23:1941-1948.

32. Corchia C, Mastroiacovo P: Health promotion in children, mothers and families: here's why we should "think about it before conception". Ital J Pediatr 2013, 39:68. epub ahead of print.

33. Gagliardi L, Rusconi F, Da Frè M, Mello G, Carnielli V, Di Lallo D, Macagno F, Miniaci S, Corchia C, Cuttini M: Pregnancy disorders leading to very preterm birth influence neonatal outcomes: results of the population-based ACTION cohort study. Pediatr Res 2013, 73:794-801.

34. Corchia C, Ferrante P, Da Frè M, Di Lallo D, Gagliardi L, Carnielli V, Miniaci S, Piga S, Macagno F, Cuttini M: Cause-specific mortality of very preterm infants and antenatal events. J Pediatr 2013, 162:1125-1132.

35. Helmerhorst FM, Perquin DA, Donker D, Keirse MJ: Perinatal outcome of singletons and twins after assisted conception: a systematic review of controlled studies. BMJ 2004, 328:261.

36. Pandey S, Shetty A, Hamilton M, Bhattacharya S, Maheshwari A: Obstetric and perinatal outcomes in singleton pregnancies resulting from IVF/ICSI: a systematic review and meta-analysis. Hum Reprod Update 2012, 18:485-503.

doi:10.1186/1471-2393-14-307

Cite this article as: Corchia et al:: Mortality and major morbidities in very preterm infants born from assisted conception or naturally conceived: results of the area-based ACTION study. BMC Pregnancy and Childbirth 2014 14:307.

\section{Submit your next manuscript to BioMed Central and take full advantage of:}

- Convenient online submission

- Thorough peer review

- No space constraints or color figure charges

- Immediate publication on acceptance

- Inclusion in PubMed, CAS, Scopus and Google Scholar

- Research which is freely available for redistribution 